\title{
Suggestions on Sustainable Development of Precision Poverty Alleviation of E-commerce in the Context of Rural Revitalization Strategy
}

\author{
Wang Yan \\ School of Accounting and Finance,Xi'an Peihua University, Xi'an City, Shaan'xi Province, China
}

303632668@qq.com

\begin{abstract}
Keywords: Rural e-commerce, Precise poverty alleviation, Sustainable development, Rural revitalization strategy.
\end{abstract}

\begin{abstract}
In recent years, e-commerce has become an important force to promote the development of "Internet + " and an important part of Chinese new economy e-commerce platform provides an effective solution to the problems existing in the development of rural areas, agricultural modernization and farmers poverty alleviation and enrichment. Poverty alleviation of e-commerce has become an important means to overcome poverty and help to promote the implementation of the strategy of rural revitalization. This paper probes into the concept and connotation of precise poverty alleviation for e-commerce, combs out practical ways of poverty alleviation for e-commerce in practice, and puts forward suggestions for sustainable development of precise poverty alleviation for e-commerce.
\end{abstract}

\section{Introduction}

On February 19, 2019, the Central Committee of the Communist Party of China and the State Council issued "Some Opinions on Adhering to Priority Development of Agriculture and Rural Areas and Doing Well the Work of"Agriculture, Countryside and Agriculture". Document No. 1 of the Central Committee clearly points out that this year and next are the decisive period for building a well-off society in an all-round way. There are many hard tasks to be accomplished in the field of agriculture, countryside and farmers. We must persist in resolving the problems of agriculture, countryside and farmers as the top priority of the Party's work. At the same time, the document proposes the implementation of digital village strategy, and further promotes "Internet+agriculture".

With the continuous development of rural e-commerce, more and more farmers get rich through e-commerce, and the rural market is gradually awakened. According to the data of China Electronic Commerce Research Center, the total retail sales of rural areas reached 1.37 trillion yuan in 2018, an increase of $30.4 \%$ compared with the same period last year; the total retail sales of agricultural products reached 230.5 billion yuan, an increase of $33.8 \%$ compared with the same period last year. The rapid development of rural e-commerce has opened up new channels for agricultural products. At the same time, with the promotion of relevant policies, the interaction between Ali, Jingdong and Pingduoduo e-commerce platforms and rural areas has become more benign, and rural e-commerce has played an increasingly important role in the process of precise poverty alleviation and rural revitalization.

\section{The Concept and Connotation of Precision Poverty Alleviation in E-commerce}

The precise poverty alleviation of the electricity supplier is to integrate the Internet plus into the poverty alleviation system of the government, through a precision poverty alleviation mechanism with multiple households and one shop with many villages, and docking the large market of urban and rural areas, paying attention to the uplink of agricultural products and promoting the circulation of commodities, so as to stimulate the poor households to increase employment and promote the coordinated development of urban and rural economy and society and achieve a win-win situation.

We should mobilize the power of the government, electricity providers, production operators and 
all sectors of society to improve the concept and system of Internet + e-business through improving the relevant infrastructure in the poverty-stricken areas. It can help farmers and producers in poverty-stricken areas to enhance their ability to use e-commerce, promote the production, processing, marketing and brand building of local agricultural products and special products, facilitate the production and life of the masses, promote local employment and entrepreneurship, increase farmers'income, and promote the transformation of economic and social development, thus speeding up the pace of poverty alleviation and prosperity.

\section{Sustainable Development Approaches of Precision Poverty Alleviation in E-commerce}

Poverty alleviation by e-commerce is the product of the development of e-commerce, and its overall development time is relatively short. It was first promoted by local governments, large-scale e-commerce platforms, e-commerce entrepreneurs selling agricultural products and social forces concerned about poverty issues in some poverty-stricken areas to explore and practice, and formed various characteristic paths of poverty alleviation by e-commerce, which ultimately promoted E-commerce poverty alleviation to become a key to poverty all Innovative carrier for revitalization.

\subsection{Poverty-stricken Subject of E-commerce Empowerment}

Poor households who are willing to engage in e-commerce can be trained appropriately, guide them to open shop online, sell their own and villagers'agricultural products independently, increase their income, and realize their own poverty alleviation. Due to the lack of leadership of e-commerce demonstration leaders, the problems that the general poor subjects dare not, will not and will not be willing to do are still prominent. At present, e-commerce poverty alleviation training has been carried out in poverty-stricken areas, but we must pay attention to the system training after training, especially the system support of e-commerce service providers, express logistics, packaging and processing, etc. We must start to build e-commerce ecology in poverty-stricken areas, otherwise it may lead to a low proportion of practically engaged in e-commerce after training.

\subsection{E-commerce Absorbs Employment of Poor People}

E-commerce and its related industries are labor-intensive industries with huge employment potential. At present, the poverty alleviation of employment for business needs to further broaden our horizons and find more opportunities in direct employment and employment in supporting industries. For example, the logistics express industry, with the rapid development of e-commerce, the sorting, packaging, handling, distribution and other links matching logistics Express also need a large number of employees. E-commerce service industry is also rising rapidly with the development of e-commerce. There is a large demand for e-commerce talents in the areas of online store customer service, art photography, data analysis, background management and so on.

\subsection{E-commerce Drives Entrepreneurship in Poverty-stricken Areas}

E-commerce is a huge ecosystem, generally including the front-end e-commerce trading system, the intermediate e-commerce service industry, express logistics, financial payment and other supporting systems, the back-end production, processing, warehousing and packaging and other basic systems, is a crisscross complex industrial cluster. In such an ecosystem, there are innumerable industrial chains and nodes, which contain innumerable opportunities for entrepreneurship.

\subsection{E-commerce Promotes Poverty Alleviation by Consumption}

Relying on e-commerce platform to carry out various forms of consumer poverty alleviation, such as crowdsourcing, pre-sale, subscription, adoption, etc., can be used in e-commerce poverty alleviation. There are some problems in poverty alleviation by consumption. The main reason is that the willingness of consumers to purchase agricultural products voluntarily in poverty-stricken areas has not been unified with the acceptance of the quality of agricultural products in poverty-stricken areas. Although some consumers may accept the rough or even defective packaging and appearance 
of agricultural products in poverty-stricken areas, as the most basic quality control that general online transactions should have, they still can not achieve. When it comes to requirements, it leads to some consumers'psychological disparities and even feels cheated. This requires poor areas to strengthen the construction of agricultural products base at the source, do a good job in standardized production, pay attention to post-natal storage and fresh-keeping, packaging sorting, brand design and other links, to enhance the experience of consumers.

\subsection{E-commerce Drives Social Assistance}

Poverty alleviation is an important force to promote poverty alleviation. Cohesion of social forces will surely speed up the pace of poverty alleviation and prosperity. As one of the three major battlefields of poverty alleviation, social poverty alleviation has been attached great importance by the central government. In the era of e-commerce, it is quicker to mobilize more social forces to participate in poverty alleviation. In practice, various e-commerce platforms have unexpectedly planned social poverty alleviation projects. For example, the Poverty Alleviation Office of the State Council supports the construction of the China Social Poverty Alleviation Network, which seeks to build five functional platforms, namely, caring assistance, e-commerce poverty alleviation, poverty alleviation, poverty alleviation demonstration and poverty alleviation model, and to build a network service platform connecting the poor and the social caring people and caring enterprises.

\section{Suggestions on Promoting the Sustainable Development of Precision Poverty Alleviation in E-commerce}

At present, e-commerce poverty alleviation has made some achievements in practice, but objectively, it still faces the following practical problems: the thinking of cadres and masses and traditional production and operation subjects needs to be changed, the Internet habits of people's production and life need to be fostered, the broadband network and express logistics of e-commerce development need to be improved, the various types of e-commerce talents urgently needed in reality need to be cultivated, and the reality of e-commerce poverty alleviation The vision of practice needs to be broadened, and the forces involved in e-commerce poverty alleviation need to be coordinated. We need to face up to it and solve it so as to promote the sustainable development of e-commerce precise poverty alleviation.

\subsection{Strengthen the Rational Understanding of Poverty Alleviation by Businessmen}

We should continue to broaden our horizons on poverty alleviation by business. We can continue to train willing poor households to open online stores. We can also continue to carry out online centralized promotion of agricultural products in poor areas. More importantly, we should consider how to combine with the long-term economic and social development of poverty-stricken areas, especially with the main objectives and precise essentials of poverty alleviation, relying on e-commerce, to help in such aspects as employment alleviation by e-commerce, industry alleviation by e-commerce, e-commerce education and public welfare alleviation by e-commerce, so as to promote the deep integration of e-commerce and poverty alleviation.

\subsection{Accelerate the Solution of the Practical Dilemma Faced by E-commerce Poverty Alleviation}

Owing to the backward network infrastructure in poor areas, e-commerce poverty alleviation often faces practical difficulties such as undeveloped express logistics, non-standard agricultural products and lack of e-commerce talents. To further promote the poverty alleviation of e-commerce, we must adhere to the problem-oriented approach, start with the shortcomings, and solve the practical difficulties faced one by one. Pay attention to the system support after training, so as to make the way of e-commerce entrepreneurship smoother. To solve the problem of reducing the cost and increasing the speed of express logistics, we should implement the concept of collaborative sharing, reduce the operating cost and raise the speed of distribution by cultivating the fourth party logistics 
and properly subsidizing the postal service. Especially, e-commerce platforms and enterprises should be promoted, starting from opening up the supply chain, extending to the innovative industrial chain, until reshaping the value chain, reforming the production system of agricultural products, and promoting the structural reform of the rural supply side.

\subsection{Attaching Importance to the Sense of Obtaining the Main Body of Poverty Alleviation Assistance in E-commerce}

We should associate the effect of e-commerce poverty alleviation with whether farmers get benefits or not, distinguish the performance of e-commerce in poor areas from that in poor areas, and combine the general e-commerce poverty alleviation activities with the long-term mechanism of e-commerce poverty alleviation. All e-commerce poverty alleviation should focus on the main body of poverty, reflect the essence of precise poverty alleviation, so that people in poor areas can truly feel the changes brought by e-commerce. To test the effectiveness of e-commerce poverty alleviation, it is necessary to see the actual role of the number of poor farmers who can lift themselves out of poverty through e-commerce, which can increase their income on average to each farmer, in the economic and social development of poverty-stricken areas and the rural revitalization.

\subsection{Establishing an Effective Coordination Mechanism for Poverty Alleviation in E-commerce}

Governments, platforms, online merchants, service providers, traditional enterprises, agricultural operators and poor households are six important participating forces in e-commerce poverty alleviation. However, from the actual situation, there is still a lack of effective coordination among the six forces and among government departments, platforms, network businesses and service providers within each force, which leads to the decentralization of e-commerce elements in poor areas, the difficulty of forming a joint force, the high operating costs and the difficulty of sustainable development. We should speed up the establishment of a new coordination mechanism of e-commerce Poverty Alleviation under the guidance of the government, open platform and participation of all parties to further enhance the efficiency of e-commerce poverty alleviation. In particular, local governments should have the concept of systematic thinking, give full play to the role of overall coordination, make good use of the e-commerce poverty alleviation policy, further improve the ecology of e-commerce, mobilize the enthusiasm of all parties to participate in e-commerce poverty alleviation, and make the role of e-commerce poverty alleviation play a more full role in poverty alleviation.

\section{Acknowledgment}

This research is financially supported by the following subjects.

1. Xi'an Social Science Planning Fund Subject in 2019: Research on Long-term Mechanism of Precision Poverty Alleviation in Rural Areas of Xi'an (19J140

2. Shaanxi Social Science Foundation Subject in 2018: Research on the Innovation Model Rural Electronic Commerce Precise Poverty Alleviation in Shaanxi (2018D19

3. Xi'an Peihua University Research Subject in 2018: Research on the Innovation Model of Agricultural Products Electronic Commerce in Shaanxi (PHKT18011

4.Shaanxi Special Scientific Research Subject of Education Department in 2017: Research on the Precise Poverty Alleviation Path of Rural Electronic Commerce in Shaanxi" (17JK1047)

\section{References}

[1] Huang Yajing. Research on Precise Poverty Alleviation Strategy of Rural E-commerce [J]. Anhui Agricultural Science, 2018 (17)

[2] Zhang Xiaheng. The Mechanism and Path of E-commerce Promoting Precision Poverty 
Alleviation in Rural Areas [J]. Journal of Beijing University of Technology (Social Science Edition), 2018 (04)

[3] Yan Qiang, Wang Guoli, Chen Jiayou. Path and Countermeasure of precise poverty alleviation for e-commerce of agricultural products: a case study of poor rural areas in Guizhou [J]. Rural economy, 2018 (02)

[4] Mou Qiuju. An Analysis of E-commerce Aiding the Precise Poverty Alleviation in Rural Areas: A Case Study of Guizhou Province [J]. Agricultural Economy, 2017 (07)

[5] Gao Guang Han, Li Wanlian, Hu Xiang Feng. Problems in the implementation of poverty alleviation projects in rural areas under the "Internet + " mode: Based on field investigation in Xupu County of Hunan Province, [J]. Hubei Agricultural Sciences, 2017 (09)

[6] Zhang Yan, Wang Xiaozhi. Study on the Mode and Countermeasure of Poverty Alleviation by E-commerce in Poverty-stricken Rural Areas [J]. Agricultural Economy, 2016 (10) 